\title{
Elevated levels of serum IL-36 $\alpha$ in patients with systemic lupus erythematosus
}

\author{
XUE-RONG WANG, JIAN-PING XIAO and DE-GUANG WANG \\ Department of Nephrology, The Second Hospital of Anhui Medical University, Hefei, Anhui 230601, P.R. China
}

Received March 20, 2021; Accepted June 11, 2021

DOI: $10.3892 /$ br.2021.1452

\begin{abstract}
The present study aimed to investigate the levels of IL-36 $\alpha$ and its association with disease activity in patients with systemic lupus erythematosus (SLE). A total of 60 patients with SLE and 29 healthy controls were enrolled in the present study. Disease activity was evaluated using the SLE disease activity index (SLEDAI). The serum levels of IL-36 $\alpha$, IL-36 receptor antagonist (IL-36Ra) and IL-17 were assessed using ELISA. The levels of IL-36 $\alpha$ in patients with SLE were significantly higher compared with those of healthy controls. There was a significant increase in IL-36 $\alpha$ in the active SLE group (SLEDAI score $\geq 5$ ) compared with that of the healthy controls $(\mathrm{P}<0.001)$. The serum IL-36 $\alpha$ levels were higher in patients with active SLE than in patients with quiescent disease $(\mathrm{P}=0.012)$. IL-36Ra was downregulated in patients with $\mathrm{SLE}(\mathrm{P}=0.007)$. The serum IL-17 levels were elevated in patients with $\operatorname{SLE}(\mathrm{P}=0.036)$, and a positive correlation was observed between the IL-36 $\alpha$ and IL-17 levels $(\mathrm{r}=0.453, \mathrm{P}=0.003)$. The serum IL-36 $\alpha$ levels were associated with SLEDAI ( $\mathrm{r}=0.374, \mathrm{P}=0.003)$, proteinuria $(\mathrm{r}=0.329, \mathrm{P}=0.010)$ and complement 3 ( $\mathrm{r}=-0.336, \mathrm{P}=0.009)$. Patients who were receiving glucocorticoid treatment had lower IL-36 $\alpha$ levels than those who were not receiving glucocorticoid treatment $(\mathrm{P}=0.003)$. Patients with lupus nephritis had higher serum IL-36 $\alpha$ levels compared with those found in patients without lupus nephritis $(\mathrm{P}=0.037)$. The serum IL-36 $\alpha$ concentration was elevated in patients with SLE, and was correlated with disease activity and IL-17 levels. The aberrant serum IL-36 $\alpha$ levels observed in the present study and its clinical association with SLE suggest the important role of IL-36 $\alpha$ in onset and progression of SLE. In addition, the association of IL-36 $\alpha$ with IL-17 level indicates its involvement in the regulation of $\mathrm{T}$ helper 17 cytokines.
\end{abstract}

\section{Introduction}

Members of the IL-1 family of cytokines are key regulators of inflammatory and innate immunity. IL-36 cytokines

Correspondence to: Dr De-Guang Wang, Department of Nephrology, The Second Hospital of Anhui Medical University, 678 Furong Road, Hefei, Anhui 230601, P.R. China

E-mail: wangdeguang@ahmu.edu.cn

Key words: IL-36 $\alpha$, IL-36 receptor antagonist, IL-17, systemic lupus erythematosus [including IL-36 $\alpha$, IL-36 $\beta$, IL-36 $\gamma$ and IL-36 receptor antagonist (IL36Ra)] are members of the IL-1 family (1). IL-36 $\alpha$ is particularly expressed in epithelium, keratinocytes, monocytes/macrophages and $\alpha \beta$ and $\gamma \delta$ T lymphocytes (1). Psoriasis and primary Sjogren's syndrome (pSS) are autoimmune-mediated inflammatory diseases. A previous study showed that IL-36 $\alpha$ was involved in the development of psoriasis, it had a pro-inflammatory effect (2). The serum levels of IL-36 $\alpha$ were significantly higher in patients with pSS compared with those in subjects complaining of dry mouth or eyes, but who did not meet the American-European Consensus Group criteria for pSS. In addition, the serum levels of IL-36 $\alpha$ were correlated with pSS disease activity (3).

Systemic lupus erythematosus (SLE) is also a common autoimmune and inflammatory disease, which is characterized by complement activation, production of numerous auto-antibodies and damage to multiple organs and tissues. A recent study reported the involvement of T helper (Th)17 cells and cytokines in the pathogenesis of SLE (4). Another study demonstrated that plasma IL-17 levels were elevated in patients with new-onset SLE, and a positive correlation was observed between plasma IL-17 and SLE disease activity index (SLEDAI) (5). Yang et al (6) found that IL-17 derived from patients with active SLE could induce the mRNA expression of adhesion molecules, and promoted the recruitment of neutrophils. In addition, IL-36 receptor (IL-36R) signaling appears to be crucial for the control of the IL-23/IL-17/IL-22 axis $(7,8)$. Carrier et al (9) demonstrated that IL-36 cytokines are upregulated by Th17 cytokines, whereas elevated IL-17 expression was observed in psoriasis. IL-36 signaling facilitates the pathogenesis of renal tubulointerstitial lesions through the activation of the NOD-, LRR- and pyrin domain-containing 3 and the IL-23/IL-17 axis (10). Previous studies found that serum IL-36 levels were elevated in patients with $\operatorname{SLE}(11,12)$. However, the role of IL-36 $\alpha$ in patients with SLE remains to be fully determined. Therefore, the present study investigated the contribution of IL-36 $\alpha$ in the development of SLE, and explored the regulatory effect of IL-36 $\alpha$ on IL-17 in patients with SLE.

\section{Materials and methods}

Study samples. Serum was obtained from patients with SLE $(n=60 ; 55$ women and 5 men; median age, 37.5 years, age range, 19-73 years) and healthy controls $(n=29 ; 25$ women and 
Table I. Comparison of clinical and laboratory parameters between the SLE and control group.

\begin{tabular}{|c|c|c|c|}
\hline Variable & SLE group, $n=60$ & Control group, $\mathrm{n}=29$ & P-value \\
\hline Anti-double stranded DNA, -/+ & $30 / 30$ & NA & NA \\
\hline Antinuclear antibodies, $-/+$ & $2 / 58$ & NA & NA \\
\hline Albumin, g/l & $31.40 \pm 8.99$ & $47.49 \pm 2.52$ & $0.01^{\mathrm{a}}$ \\
\hline Creatinine, $\mu \mathrm{mol} / 1^{\mathrm{e}}$ & $66.00(51.25,117.75)$ & $56.00(50.00,70.50)$ & 0.087 \\
\hline Proteinuria, $\mathrm{mg} / 24 \mathrm{~h}^{\mathrm{e}}$ & $660(237.5-3062.5)$ & NA & NA \\
\hline $\mathrm{C} 3, \mathrm{~g} / \mathrm{l}^{\mathrm{e}}$ & $0.68(0.44-0.93)$ & NA & NA \\
\hline $\mathrm{C} 4, \mathrm{~g} / \mathrm{l}^{\mathrm{e}}$ & $0.09(0.05-0.22)$ & NA & NA \\
\hline $\mathrm{IgG}, \mathrm{g} / \mathrm{l}^{\mathrm{e}}$ & $14.75(11.54-19.45)$ & NA & NA \\
\hline $\operatorname{IgA}, \mathrm{g} / \mathrm{l}^{\mathrm{e}}$ & $2.48(1.51-3.28)$ & NA & NA \\
\hline $\operatorname{IgM}, \mathrm{g} / \mathrm{l}^{\mathrm{e}}$ & $0.95(0.75-1.35)$ & NA & NA \\
\hline Erythrocyte sedimentation rate, $\mathrm{mm} / \mathrm{h}^{\mathrm{e}}$ & $40.00(22.25-69.25)$ & NA & NA \\
\hline SLEDAI $^{\mathrm{e}}$ & $10.00(6.00-17.50)$ & NA & NA \\
\hline Received glucocorticoids ${ }^{\mathrm{f}}, \mathrm{n}(\%)$ & $45(75)$ & NA & NA \\
\hline Received glucocorticoids or immunosuppressants ${ }^{\mathrm{g}}, \mathrm{n}(\%)$ & $40(66.67)$ & NA & NA \\
\hline $\mathrm{IL}-36 \alpha, \mathrm{pg} / \mathrm{ml}^{\mathrm{e}}$ & $50.08(39.01-108.02)$ & $25.98(17.19-32.1)$ & $0.000^{c}$ \\
\hline IL-36Ra, $\mathrm{pg} / \mathrm{ml}^{\mathrm{e}}$ & $42.6(29.73-107.08)$ & $110.45(45.72-160.95)$ & $0.007^{\mathrm{b}}$ \\
\hline IL-17, pg/ml ${ }^{\mathrm{e}}$ & $39.68(33.03-82.44)$ & $35.13(32.14-41.25)$ & $0.036^{\mathrm{a}}$ \\
\hline
\end{tabular}

${ }^{\mathrm{a}} \mathrm{P}<0.05$; ${ }^{\mathrm{b}}<0.01 ;{ }^{\mathrm{c}} \mathrm{P}<0.001$; ${ }^{\mathrm{d}}$ mean \pm standard deviation; ${ }^{\mathrm{e}}$ median (interquartile range); ${ }^{\mathrm{f}}$ glucocorticoids administered include hydrogenated prednisolone, prednisolone acetate, methylprednisolone; gimmunosuppressants administered include Cyclophosphamide, Mycophenolatemofetil and Tacrolimus. NA, not applicable; IL-36Ra, IL-36 receptor antagonist; SLE, systemic lupus erythematosus; SLEDAI, SLE disease activity index.

4 men; median age, 32.0 years, age range, 24-45 years) across two centers: The Department of Nephrology of The First and Second Affiliated Hospitals of Anhui Medical University, and the Department of Rheumatology of The Second Hospital of Anhui Medical University). Patients who had suffered various types of malignancy or severe inflammation were excluded from the present study. Healthy controls were selected from the Health Examination Center of The Second Hospital of Anhui Medical University. The diagnosis of SLE cases was based on the American College of Rheumatology 1997 revised criteria for SLE (13). The SLEDAI was used to assess disease activity. A SLEDAI score $\geq 5$ was defined as active SLE, whereas a SLEDAI score $<5$ was defined as inactive SLE (14). Patients with lupus nephritis were defined by persistent proteinuria $(>0.5 \mathrm{~g} / 24 \mathrm{~h})$ or persistent hematuria, presence of cellular casts or renal biopsy supporting (14). All procedures performed in the present study involving human participants were performed in accordance with the Ethical Standards of the Ethics Committee for Human Research at the Second Hospital of Anhui Medical University as well as in accordance with the 1964 Helsinki Declaration and its later amendments or comparable ethical standards (15). The present study was approved by the Ethics Committee for Human Research at The Second Hospital of Anhui Medical University (approval no.PJ-YX2017-013), and all the participants provided written informed consent prior to being enrolled in the study.

Biochemical measurements. The patients were made to fast for $8 \mathrm{~h}$ after dinner in the night. The fasting blood samples were drawn in the morning, as the blood was also used to measured alanine aminotransferase levels for patients. Blood samples were also collected for determination of albumin, creatinine, complement, immunoglobulin ( $\mathrm{IgG})$, erythrocyte sedimentation rate (ESR) and extractable nuclear antigen polypeptide antibodies [antinuclear antibodies, double-stranded (ds) DNA antibodies] all of which were routine examinations. Serum was isolated and stored at $-80^{\circ} \mathrm{C}$ for measuring IL-36 $\alpha$, IL-36Ra and IL-17 levels. The IL-36 $\alpha$ levels (Cusabio Biotech; cat. no. CSB-E1011617HU), serum IL-36Ra (Cusabio Biotech; cat. no. CSB-EL011616HU) and IL-17 (R\&D Systems, Inc.; cat. no. D1700) levels were measured using human ELISA kits.

Statistical analysis. Data were analyzed using SPSS version 16 (IBM Corp.). The data are presented as the mean \pm standard deviation for normally distributed variables, or as the median and interquartile ranges otherwise. Differences between two groups were assessed either by an independent samples Student's t-test or by a Wilcoxon's rank sum test for continuous variables. Correlations between two variables were assessed by Spearman's rank correlation. Two-sided $\mathrm{P}<0.05$ was considered to indicate a statistically significant difference.

\section{Results}

In total, 60 patients with SLE, including 47 active patients and 13 inactive patients, and 29 healthy controls were enrolled in the present study. All patients and healthy controls were Chinese. There were no significant differences between patients with SLE and normal controls in terms of age, sex or creatinine levels (Table I). Baseline disease activity $(n=60)$ was highly variable, with SLEDAI scores ranging from 0-36, and a median of 10.58 patients had positive ANA, whereas 30 patients with SLE had positive double-stranded (ds) DNA (Table I). The majority of patients $(75 \%)$ received prednisone or an equivalent glucocorticoid. In total, 40 patients 
Table II.Association between plasma IL-36 $\alpha$ levels and clinical and laboratory parameters in the patients with systemic lupus erythematosus.

\begin{tabular}{|c|c|c|c|}
\hline Parameters & $\mathrm{n}$ & $\begin{array}{l}\text { Serum IL-36 } \alpha \\
\text { level, pg/ml, } \\
\text { median } \\
\text { (interquartile } \\
\text { range) }\end{array}$ & P-value \\
\hline Rash & & & $0.003^{\mathrm{b}}$ \\
\hline Yes & 36 & $69.35(42.74-141.75)$ & \\
\hline No & 24 & $41.23(30.58-59.62)$ & \\
\hline Arthritis & & & 0.382 \\
\hline Yes & 22 & $53.59(40.14-140.74)$ & \\
\hline No & 38 & $49.83(32.66-95.08)$ & \\
\hline Oral ulcer & & & 0.647 \\
\hline Yes & 13 & $58.68(32.70-145.68)$ & \\
\hline No & 47 & 49.14 (39.11-106.98) & \\
\hline $\begin{array}{l}\text { Nervous system } \\
\text { disorder }\end{array}$ & & & 0.597 \\
\hline Yes & 4 & $55.96(21.48-114.11)$ & \\
\hline No & 56 & $50.08(39.44-108.02)$ & \\
\hline Pleuritis & & & 0.405 \\
\hline Yes & 10 & $71.10(40.10-127.37)$ & \\
\hline No & 50 & $49.39(37.95-105.4)$ & \\
\hline Pericarditis & & & 0.555 \\
\hline Yes & 6 & $51.34(39.60-107.32)$ & \\
\hline No & 54 & $49.39(37.95-107.32)$ & \\
\hline Lymphopenia & & & $0.007^{\mathrm{b}}$ \\
\hline Yes & 17 & $79.70(48.73-158.64)$ & \\
\hline No & 43 & 44.68 (32.72-77) & \\
\hline Thrombocytopenia & & & 0.085 \\
\hline Yes & 24 & $119.61(58.31-165.61)$ & \\
\hline No & 36 & $45.12(32.35-76.09)$ & \\
\hline ESR & & & $0.001^{\mathrm{b}}$ \\
\hline Yes & 33 & $77.0(43.16-150.60)$ & \\
\hline No & 27 & $42.37(31.24-49.64)$ & \\
\hline Hypocomplementemia & & & $0.025^{\mathrm{a}}$ \\
\hline Yes & 40 & $62.43(39.59-123.46)$ & \\
\hline No & 20 & $43.03(28.48-56.52)$ & \\
\hline \multicolumn{4}{|l|}{$\begin{array}{l}\text { Anti-double } \\
\text { stranded-DNA }\end{array}$} \\
\hline positive & & & $0.019^{\mathrm{a}}$ \\
\hline Yes & 30 & $58.63(40.57-150.16)$ & \\
\hline No & 30 & $43.68(35.05-75.79)$ & \\
\hline Proteinuria & & & $0.037^{\mathrm{a}}$ \\
\hline Yes & 45 & $63.19(39.66-123.44)$ & \\
\hline No & 15 & $42.63(32.72-53.46)$ & \\
\hline Hematuresis & & & $0.027^{\mathrm{a}}$ \\
\hline Yes & 24 & $55.40(39.01-132.48)$ & \\
\hline No & 36 & $44.34(36.25-87.91)$ & \\
\hline $\begin{array}{l}\text { Antinuclear antibodies } \\
\text { positive }\end{array}$ & & & 0.538 \\
\hline Yes & 56 & $51.34(39.59-108.02)$ & \\
\hline No & 4 & $36.28(31.61-182.15)$ & \\
\hline
\end{tabular}

${ }^{\mathrm{a}} \mathrm{P}<0.05 ;{ }^{\mathrm{b}} \mathrm{P}<0.01$.
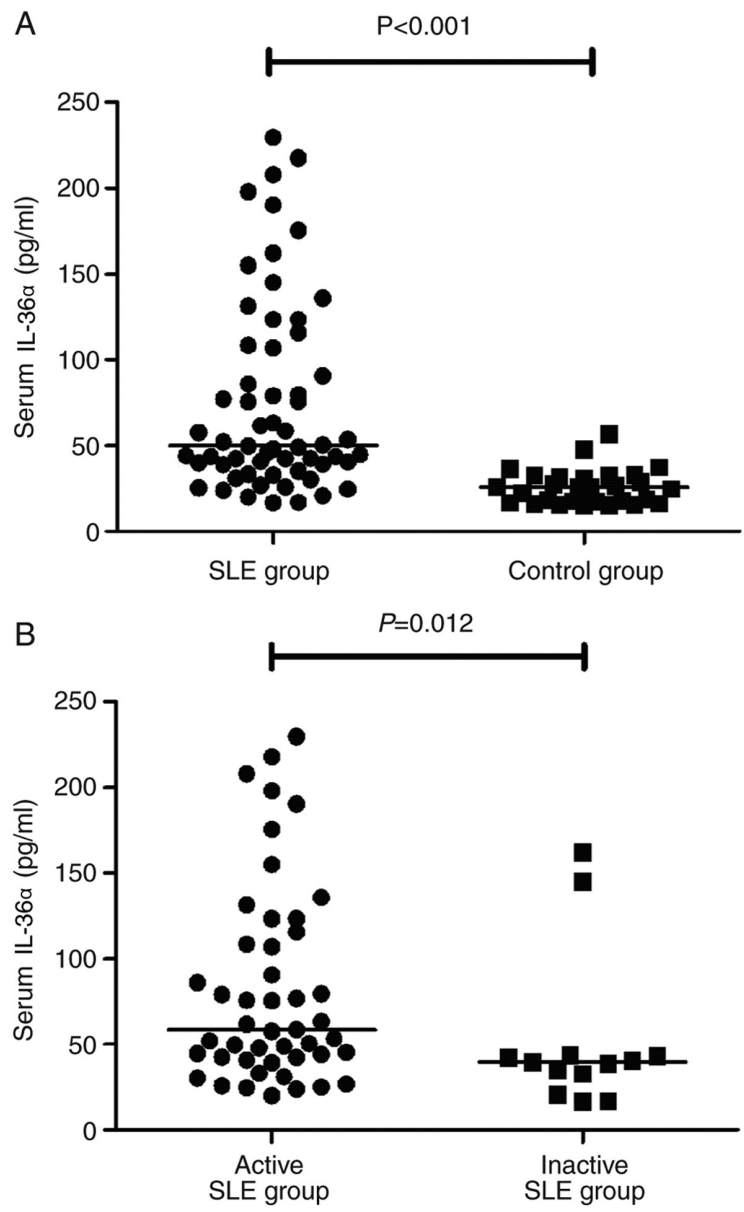

Figure 1. Comparison of IL-36 $\alpha$ levels. (A) Level of serum IL-36 $\alpha$ were significantly elevated in patients with SLE compared to the healthy controls $(\mathrm{P}<0.001)$. (B) Patients with active SLE had higher IL-36 $\alpha$ levels compared with the patients with inactive SLE ( $\mathrm{P}=0.012)$. SLE, systemic lupus erythematosus.

$(66.67 \%)$ received glucocorticoids and immunosuppressant (Table I).

The association between serum IL-36 $\alpha$ levels with the clinical and laboratory parameters of patients with SLE were analyzed, and the results showed that rash, leukocytes, ESR, anti-dsDNA, proteinuria and hematuresis were positively associated with the serum IL-36 $\alpha$ levels in patients with SLE (Table II). A negative correlation was observed between complement 3 and serum IL-36 $\alpha$ levels. No significant associations between IL-36 $\alpha$ with any other clinical or laboratory parameters were observed ( $\mathrm{P}>0.05$; Table II).

Serum IL-36 $\alpha$ levels were significantly higher in patients with SLE than in healthy controls [median (interquartile range); 50.08 (39.01-108.02) pg/ml vs. 25.98 (17.19-32.1) pg/ml; $\mathrm{P}<0.001)$ ], as shown in Fig. 1A. The serum IL-36 $\alpha$ levels were significantly higher in the active group compared with those in the inactive group $(\mathrm{P}=0.012)$, as shown in Fig. 1B. Serum IL-36Ra levels were significantly lower in patients with SLE than in controls [42.6 (29.73-107.08) pg/ml vs. 110.45 (45.72-160.95) pg/ml, $\mathrm{P}=0.007)$ ], as shown in Fig. 2A, and it was lower in patients with active SLE compared with the levels found in patients with inactive SLE ( $\mathrm{P}=0.018$, Fig. 2B). Serum IL-17 levels were increased in patients with SLE (Fig. 3), but there was no significant difference between patients with active and inactive SLE. 

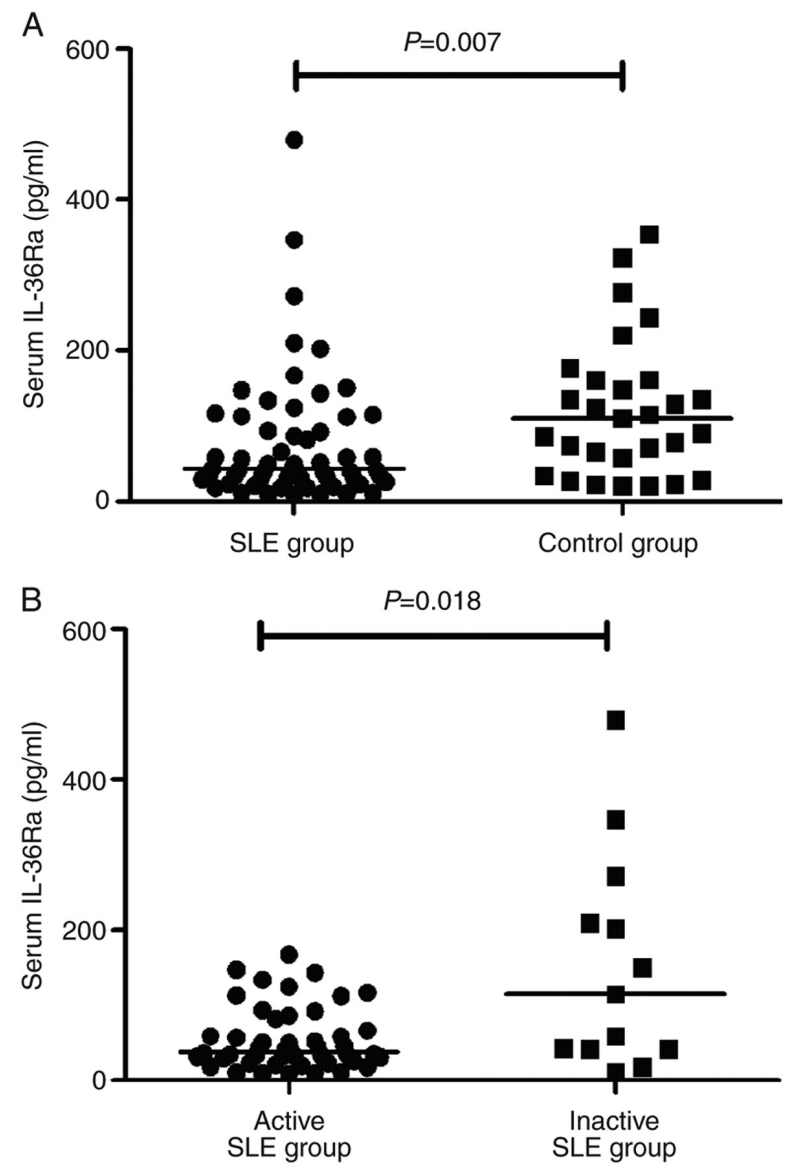

Figure 2. Serum IL-36Ra levels in patients with SLE. (A) Serum IL-36Ra levels were lower in patients with SLE compared with the controls $(\mathrm{P}=0.007)$. (B) The concentration of serum IL-36Ra was higher in patients with active SLE compared with the patients with inactive SLE $(\mathrm{P}=0.018)$. SLE, systemic lupus erythematosus.

To determine the association between serum IL-36a levels and disease activity, the association between these two parameters was analyzed. A positive correlation between serum IL-36 $\alpha$ and the SLEDAI score was observed $(r=0.374$, $\mathrm{P}=0.003$ ). In the correlation analysis shown in Fig. 4, the concentration of serum IL-36 $\alpha$ was positively correlated with proteinuria $(\mathrm{r}=0.329, \mathrm{P}=0.010)$.

The present study investigated the association between IL-36 $\alpha$ levels with serum IL-17 levels. Serum IL-36 $\alpha$ was positively correlated with IL-17 ( $\mathrm{r}=0.453, \mathrm{P}=0.003$; Fig. 4). Serum IL-36 $\alpha$ levels showed an inverse correlation with complement 3 ( $\mathrm{r}=-0.336, \mathrm{P}=0.009$; Fig. 4). There was no significant correlation between serum IL-36 $\alpha$ and $\operatorname{IgG}, \operatorname{IgA}$, IgE, IgM, complement 4 or ESR (data not shown).

In total, 45 patients received glucocorticoid treatment, whereas 40 patients with SLE received immunosuppressant and glucocorticoid therapies. Patients $(n=45)$ who had received glucocorticoid treatment had lower IL-36 $\alpha$ levels compared with those of patients who had not received glucocorticoid treatment $(\mathrm{P}=0.003$; Fig. 5). These results suggested that immunosuppressant and glucocorticoid therapies may have an inhibitory effect on IL-36 $\alpha$. A total of 47 patients $(78.33 \%)$ had renal involvement. Patients with nephritis had higher serum IL-36 $\alpha$ levels than those without nephritis $(\mathrm{P}=0.037$; Table II). Serum IL-36Ra levels were significantly
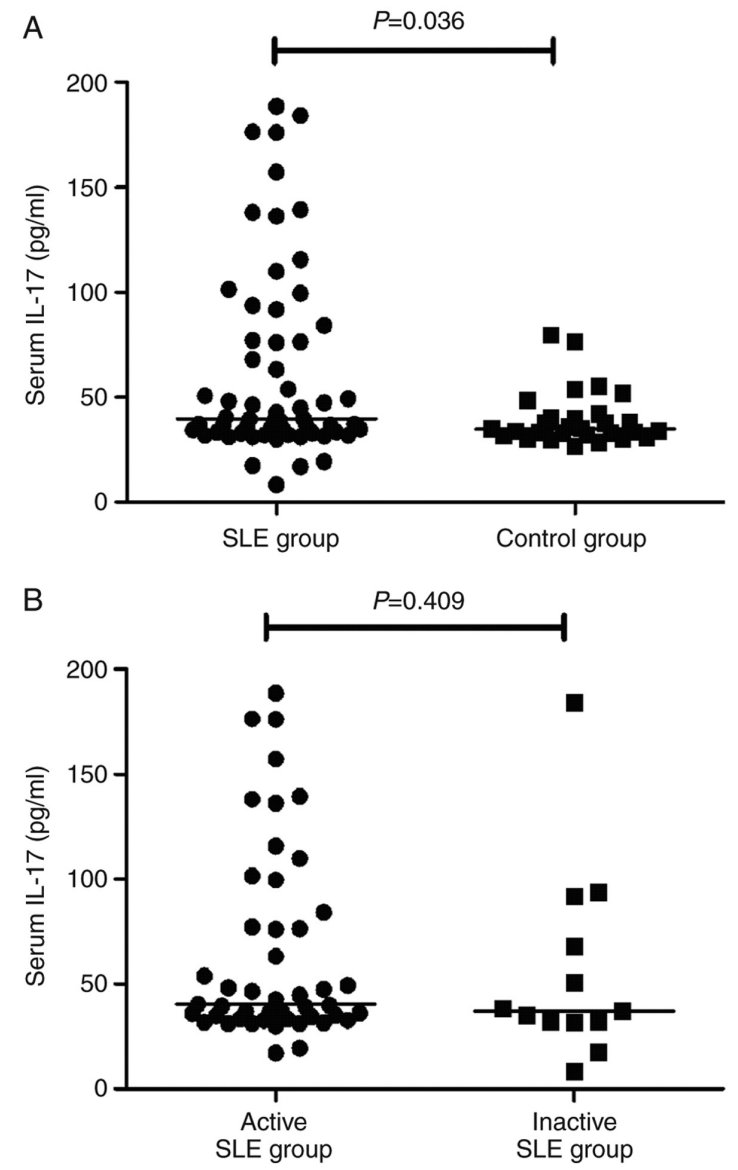

Figure 3. Serum IL-17 levels in patients with SLE. (A) Serum IL-17 levels were higher in the patients with SLE compared with the controls $(\mathrm{P}=0.036)$. (B) There was no difference in the serum IL-17 levels between the active group and inactive group. SLE, systemic lupus erythematosus.

lower in patients with SLE than in controls. IL-36Ra levels were negatively correlated with SLEDAI ( $r=-0.360, \mathrm{P}=0.001)$. There was no significant association between IL-36Ra levels and proteinuria, ESR, C3 or C4.

\section{Discussion}

A previous study demonstrated that IL-36 $\alpha$ binds to a functional heterodimeric receptor complex, which consists of IL-36R, IL-1 receptor (IL-1R)-related protein 2 and IL-1R accessory protein, and activates $\mathrm{NF}-\kappa \mathrm{B}$ and MAPK to initiate pro-inflammatory pathways (16).

IL-36 $\alpha$ is expressed in epithelium and keratinocytes. A previous study indicated that IL-36 $\alpha$ may be involved in the pathogenesis of autoimmune disease (2). Previous studies reported that IL-36 $\alpha$ exerts pro-inflammatory effects in the skin of patients with psoriasis, who exhibit autoimmune-mediated inflammatory skin lesions (2,17). IL-36 is upregulated in skin lesions caused by psoriasis $(18,19)$. Moreover, transgenic mice overexpressing IL-36 $\alpha$ in keratinocytes showed certain similarities to human psoriasis (20).

Although the pathogenesis of SLE is not fully understood, cytokine-mediated immunity plays an important role in SLE $(4,5)$. Currently, little is known regarding the association between IL-36 $\alpha$ and SLE. The results of thew present study showed that the serum IL-36 $\alpha$ levels were significantly higher 
A
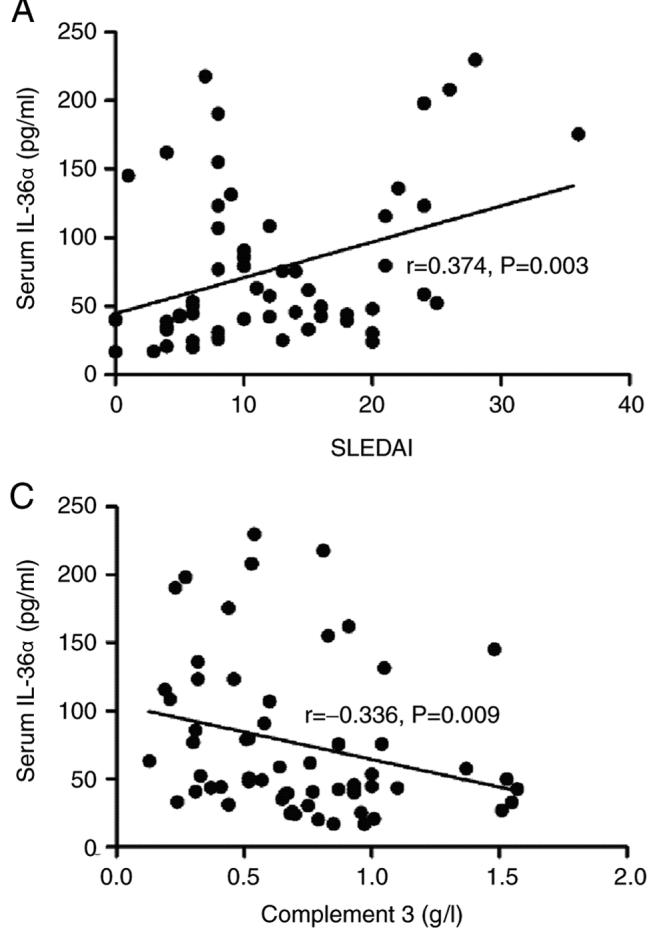

B
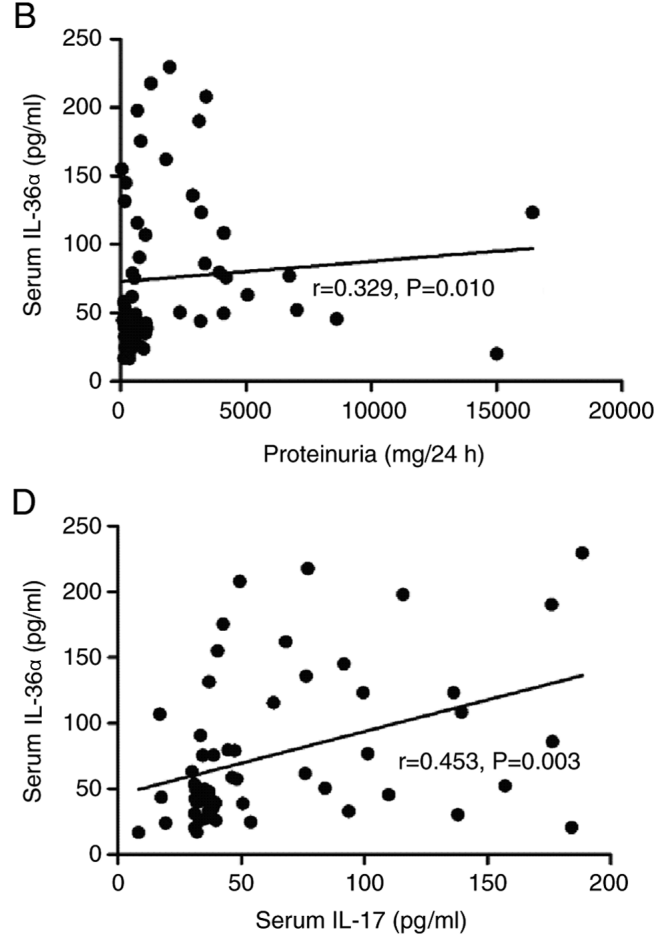

Figure 4. Correlation between serum IL-36 $\alpha$ and other factors. A significant correlation was observed between serum IL-36 $\alpha$ levels and the (A) SLEDAI score $(\mathrm{r}=0.374, \mathrm{P}=0.003),(\mathrm{B})$ proteinuria $(\mathrm{r}=0.329, \mathrm{P}=0.010),(\mathrm{C}) \mathrm{C} 3(\mathrm{r}=-0.336, \mathrm{P}=0.009)$ and $(\mathrm{D}) \mathrm{IL}-17$ ( $\mathrm{r}=0.453, \mathrm{P}=0.003)$. SLEDAI, systemic lupus erythematosus disease activity score.

A

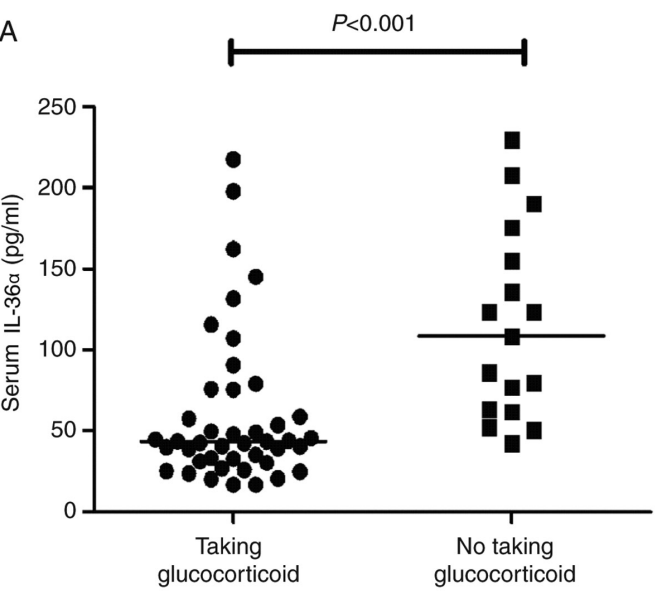

B

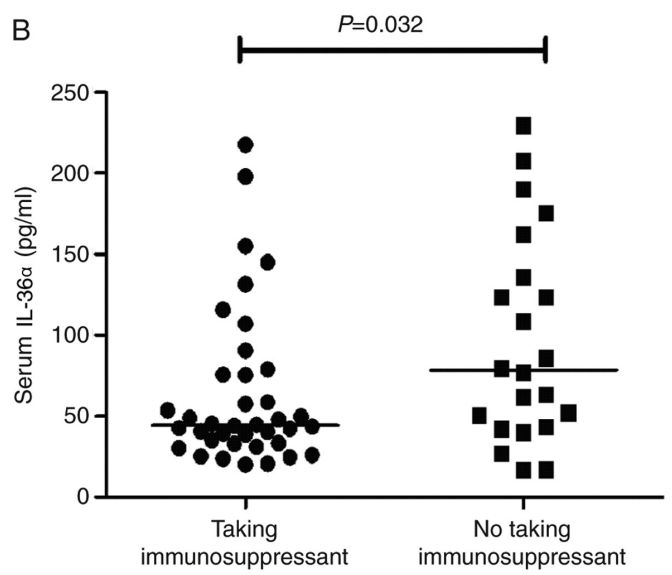

Figure 5. Effect of glucocorticoids and immunosuppressants on IL-36 $\alpha$ levels in patients with SLE. (A) Patients taking glucocorticoids had lower serum IL-36 $\alpha$ levels than those not taking them $(\mathrm{P}<0.001)$. (B) Lower IL-36 $\alpha$ levels were also observed in patients taking immunosuppressants $(\mathrm{P}=0.032)$. in patients with SLE compared with those of the controls, and the serum IL-36 $\alpha$ levels were increased in the active SLE group compared with those of the inactive group. Circulating IL-36 $\alpha$ levels were correlated with SLEDAI, complement 3 and ESR. These results suggested that IL-36 may be involved in the pathogenesis and progression of SLE.

Studies have shown that glucocorticoids downregulate the serum levels of IL-12 family cytokines and IL-37 $(21,22)$. The most important mechanism by which glucocorticoids exert their anti-inflammatory effects is considered to be the inhibition of the NF- $\kappa \mathrm{B}$ activity $(21,22)$. In the present study, patients who were receiving glucocorticoid or immunosuppressant therapy had lower IL-36 $\alpha$ levels, indicating that glucocorticoids or immunosuppressants may inhibit the production of IL-36 $\alpha$. Zhang et al (23) found that serum IL-36 levels in patients with SLE did not differ significantly from that of the controls. There are several possible reasons for such inconsistent results. Firstly, the patients in the current study were primarily in the active state. Furthermore, IL-36 $\alpha$ rather than all IL-36 cytokines serve an important role in autoimmune diseases $(9,24)$.

A positive correlation between serum IL-36 $\alpha$ levels and proteinuria was observed in the present study. Patients with kidney involvement had higher serum IL-36 levels. In agreement with the present study, overexpression of IL-36 $\alpha$ (IL-1F6) in the kidney led to increased expression of IL- 6 , TGF- $\beta$ receptor-1 and mesenchymal markers, and aggravated tumor-infiltrating lymphocytes in a B6.MRLc1 model (25). In addition, overexpression of IL-36 $\alpha$ upregulated $\alpha$-smooth muscle actin expression. Further studies are required to investigate the expression of IL-36 $\alpha$ in lupus nephritis.

IL-17 secretion is primarily derived from Th17 cells, which are $\mathrm{CD}^{+}$Th cells that produce IL-17, but not Th1 or 
Th2 cytokines. Several studies have reported elevated serum IL-17a levels in patients with SLE compared with the levels found in healthy controls $(26,27)$. Although it was not previously reported, the strong correlation between serum IL-36 $\alpha$ and IL-17 levels that was found in the present study was expected, since IL-36 $\alpha$ acts as a pro-inflammatory cytokine, upregulating pro-inflammatory mediators, such as IL-6, IL-8 and TNF- $\alpha$, and, in combination with TGF- $\beta$, may induce naive $\mathrm{T}$ cells to differentiate into Th17 cells (28-31). This observation suggests that IL-36 $\alpha$ may affect the Th17 cell response in patients with lupus.

IL-36Ra, which is an endogenous receptor antagonist, displays $50 \%$ amino acid sequence homology with IL-1Ra (32). IL-36Ra binds to IL-36R, but does not induce any cellular response. It prevents the interaction of IL-36 $\alpha$, IL-36 $\beta$ and IL-36 $\gamma$ with IL-36R, and thus acts as a endogenous inhibitor (33). In the present study, serum IL-36Ra levels were lower in patients with SLE than in the controls. The results of the present study support the hypothesis that the underlying mechanism of IL-36Ra deficiency leading to the progression of SLE results from the reduced suppressing effect of IL-36Ra on IL-36 $\alpha$ responses. This imbalance of IL-36 $\alpha$ and IL-36Ra would result in a pathologically increased Th17 response, which is associated with SLE.

The present study recruited 60 patients with SLE and 29 healthy subjects as the control group. This was a relatively small sample size, which may be considered a limitation of the present study. Larger sample sizes are being recruited/collected for more accurate and representative comparisons in future studies.

In conclusion, the present study confirmed that IL-36 $\alpha$ was associated with SLE and may be involved in the regulation of Th17 cytokines. Antagonism of IL-36 $\alpha$ should be explored as a treatment of SLE. Lower IL-36Ra levels resulted in a reduced inhibitory effect on IL-36 $\alpha$ and contributed to SLE development.

\section{Acknowledgements}

Not applicable.

\section{Funding}

This study was supported by funding from the Natural Science Foundation of Anhui Province (grant no. 1508085MH148), the China Postdoctoral Science Foundation funded project (grant no. 2012M511399) and the Clinical Research Cultivation Program of The Second Hospital of Anhui Medical University Foundation (grant no. 2020LCYB06).

\section{Availability of data and materials}

The datasets used and/or analyzed during the present study are available from the corresponding author on reasonable request.

\section{Authors' contributions}

DGW conceived and designed the study. XRW and JPX performed the experiments and wrote the manuscript. All authors have read and approved the final manuscript. DGW,
XRW and JPX confirm the authenticity of all the raw data. All authors read and approved the final manuscript.

\section{Ethics approval and consent to participate}

All procedures performed in the present study involving human participants were performed in accordance with the Ethical Standards of the Ethics Committee for Human Research at the Second Hospital of Anhui Medical University as well as in accordance with the 1964 Helsinki Declaration and its later amendments or comparable ethical standards. The present study was approved by the Ethics Committee for Human Research at The Second Hospital of Anhui Medical University (approval no.PJ-YX2017-013), and all the participants provided written informed consent prior to being enrolled in the study.

\section{Patient consent for publication}

Not applicable.

\section{Competing interests}

The authors declare that they have no competing interests.

\section{References}

1. van de Veerdonk FL and Netea MG: New insights in the immunobiology of IL-1 family members. Front Immunol 4: 167, 2013.

2. Tortola L, Rosenwald E, Abel B, Blumberg H, Schäfer M, Coyle AJ, Renauld JC, Werner S, Kisielow J and Kopf M: Psoriasiform dermatitis is driven by IL-36-mediated DC-keratinocyte crosstalk. J Clin Invest 122: 3965-3976, 2012

3. Ciccia F, Accardo-Palumbo A, Alessandro R, Alessandri C, Priori R, Guggino G, Raimondo S, Carubbi F, Valesini G, Giacomelli R, et al: Interleukin-36 $\alpha$ axis is modulated in patients with primary Sjögren's syndrome. Clin Exp Immunol 181: 230-238, 2015.

4. Perry D, Peck AB, Carcamo WC, Morel L and Nguyen CQ: The current concept of $\mathrm{T}(\mathrm{h}) 17$ cells and their expanding role in systemic lupus erythematosus. Arthritis (Egypt) 2011: 810649, 2011.

5. Chen XQ, Yu YC, Deng HH, Sun JZ, Dai Z, Wu YW and Yang M: Plasma IL-17A is increased in new-onset SLE patients and associated with disease activity. J Clin Immunol 30: 221-225, 2010.

6. Yang J, Chu Y, Yang X, Gao D, Zhu L, Yang X, Wan L and Li M: Th17 and natural Treg cell population dynamics in systemic lupus erythematosus. Arthritis Rheum 60: 1472-1483, 2009.

7. Gresnigt MS and van de Veerdonk FL: Biology of IL-36 cytokines and their role in disease. Semin Immunol 25: 458-465, 2013.

8. Gresnigt MS, Rösler B, Jacobs CW, Becker KL Joosten LA, van der Meer JW, Netea MG, Dinarello CA and van de Veerdonk FL: The IL-36 receptor pathway regulates Aspergillus fumigatus-induced Th1 and Th17 responses. Eur J Immunol 43: 416-426, 2013.

9. Carrier Y, Ma HL, Ramon HE, Napierata L, Small C, O'Toole M, Young DA, Fouser LA, Nickerson-Nutter C, Collins M, et al: Inter-regulation of Th17 cytokines and the IL-36 cytokines in vitro and in vivo: Implications in psoriasis pathogenesis. $J$ Invest Dermatol 131: 2428-2437, 2011.

10. Chi HH, Hua KF, Lin YC, Chu CL, Hsieh CY, Hsu YJ, Ka SM, Tsai YL, Liu FC and Chen A: IL-36 signaling facilitates activation of the NLRP3 inflammasome and IL-23/IL-17 axis in renal inflammation and fibrosis. J Am Soc Nephrol 28: 2022-2037, 2017.

11. Mai SZ, Li CJ, Xie XY, Xiong H, Xu M, Zeng FQ, Guo Q and Han YF: Increased serum IL-36 $\alpha$ and IL-36 $\gamma$ levels in patients with systemic lupus erythematosus: Association with disease activity and arthritis. Int Immunopharmacol 58: 103-108, 2018.

12. Chu M, Wong CK, Cai Z, Dong J, Jiao D, Kam NW, Lam CW and Tam LS: Elevated expression and pro-inflammatory activity of IL-36 in patients with systemic lupus erythematosus. Molecules 20: 19588-19604, 2015. 
13. Hochberg MC: Updating the American College of Rheumatology revised criteria for the classification of systemic lupus erythematosus. Arthritis Rheum 40: 1725, 1997.

14. Bombardier C, Gladman DD, Urowitz MB, Caron D, Chang CH: Derivation of the SLEDAI. A disease activity index for lupus patients. The Committee on Prognosis Studies in SLE. Arthritis Rheum 35: 630-640, 1992.

15. Gandevia B and Tovell A: Declaration Of Helsinki. Med J Aust 2: 320-321, 1964

16. Towne JE, Garka KE, Renshaw BR, Virca GD and Sims JE: Interleukin (IL)-1F6, IL-1F8, and IL-1F9 signal through IL-1Rrp2 and IL-1RAcP to activate the pathway leading to NF-kappaB and MAPKs. J Biol Chem 279: 13677-13688, 2004.

17. Frey S, Derer A, Messbacher ME, Baeten DL, Bugatti S, Montecucco C, Schett G and Hueber AJ: The novel cytokine interleukin-36 $\alpha$ is expressed in psoriatic and rheumatoid arthritis synovium. Ann Rheum Dis 72: 1569-1574, 2013.

18. Debets R, Timans JC, Homey B, Zurawski S, Sana TR, Lo S, Wagner J, Edwards G, Clifford T, Menon S, et al: Two novel IL-1 family members, IL-1 delta and IL-1 epsilon, function as an antagonist and agonist of NF-kappa B activation through the orphan IL-1 receptor-related protein 2. J Immunol 167: 1440-1446, 2001.

19. Zhou X, Krueger JG, Kao MC, Lee E, Du F, Menter A, Wong WH and Bowcock AM: Novel mechanisms of T-cell and dendritic cell activation revealed by profiling of psoriasis on the 63,100-element oligonucleotide array. Physiol Genomics 13: 69-78, 2003.

20. Blumberg H, Dinh H, Trueblood ES, Pretorius J, Kugler D, Weng N, Kanaly ST, Towne JE, Willis CR, Kuechle MK, et al: Opposing activities of two novel members of the IL-1 ligand family regulate skin inflammation. J Exp Med 204: 2603-2614, 2007.

21. Qiu F, Song L, Yang N and Li X: Glucocorticoid downregulates expression of IL-12 family cytokines in systemic lupus erythematosus patients. Lupus 22: 1011-1016, 2013.

22. Song L, Qiu F, Fan Y, Ding F, Liu H, Shu Q, Liu W and Li X: Glucocorticoid regulates interleukin-37 in systemic lupus erythematosus. J Clin Immunol 33: 111-117, 2013.

23. Zhang M, Xu WD, Zhu Y, Wen PF, Leng RX, Pan HF and Ye DQ: Serum levels of cytokines in systemic lupus erythematosus: Association study in a Chinese population. Z Rheumatol 73: 277-280, 2013.
24. Maddur MS, Miossec P, Kaveri SV and Bayry J: Th17 cells: Biology, pathogenesis of autoimmune and inflammatory diseases, and therapeutic strategies. Am J Pathol 181: 8-18, 2012.

25. Ichii O, Otsuka S, Sasaki N, Yabuki A, Ohta H, Takiguchi M, Hashimoto Y, Endoh D and Kon Y: Local overexpression of interleukin-1 family, member 6 relates to the development of tubulointerstitial lesions. Lab Invest 90: 459-475, 2010.

26. Wong CK, Lit LC, Tam LS, Li EK, Wong PT and Lam CW: Hyperproduction of IL-23 and IL-17 in patients with systemic lupus erythematosus: Implications for Th17-mediated inflammation in auto-immunity. Clin Immunol 127: 385-393, 2008.

27. Wong CK, Ho CY, Li EK and Lam CW: Elevation of proinflammatory cytokine (IL-18, IL-17, IL-12) and Th2 cytokine (IL-4) concentrations in patients with systemic lupus erythematosus. Lupus 9: 589-593, 2000.

28. Veldhoen M, Hocking RJ, Atkins CJ, Locksley RM and Stockinger B: TGFbeta in the context of an inflammatory cytokine milieu supports de novo differentiation of IL-17-producing T cells. Immunity 24: 179-189, 2006

29. Nalbandian A, Crispín JC and Tsokos GC: Interleukin-17 and systemic lupus erythematosus: Current concepts. Clin Exp Immunol 157: 209-215, 2009.

30. Bettelli E, Carrier Y, Gao W, Korn T, Strom TB, Oukka M, Weiner HL and Kuchroo VK: Reciprocal developmental pathways for the generation of pathogenic effector TH17 and regulatory T cells. Nature 441: 235-238, 2006.

31. Mangan PR, Harrington LE, O'Quinn DB, Helms WS, Bullard DC, Elson CO, Hatton RD, Wahl SM, Schoeb TR and Weaver CT: Transforming growth factor-beta induces development of the T(H)17 lineage. Nature 441: 231-234, 2006.

32. Nicklin MJ: Finally, function for 'IL-1Fs'. Blood 118: 5713-5714, 2011.

33. Towne JE, Renshaw BR, Douangpanya J, Lipsky BP, Shen M, Gabel CA and Sims JE: Interleukin-36 (IL-36) ligands require

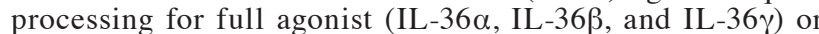
antagonist (IL-36Ra) activity. J Biol Chem 286: 42594-42602, 2011. 